\title{
Structural and functional characterisation of KNNS-BNKZ lead-free piezoceramics
}

DOI:

10.1080/17436753.2017.1366733

\section{Document Version}

Accepted author manuscript

Link to publication record in Manchester Research Explorer

\section{Citation for published version (APA):}

Hall, D., \& Tangsritrakul, J. (2018). Structural and functional characterisation of KNNS-BNKZ lead-free piezoceramics. Advances in Applied Ceramics, [dx.doi.org/10.1080/17436753.2017.1366733]. https://doi.org/10.1080/17436753.2017.1366733

\section{Published in:}

Advances in Applied Ceramics

\section{Citing this paper}

Please note that where the full-text provided on Manchester Research Explorer is the Author Accepted Manuscript or Proof version this may differ from the final Published version. If citing, it is advised that you check and use the publisher's definitive version.

\section{General rights}

Copyright and moral rights for the publications made accessible in the Research Explorer are retained by the authors and/or other copyright owners and it is a condition of accessing publications that users recognise and abide by the legal requirements associated with these rights.

\section{Takedown policy}

If you believe that this document breaches copyright please refer to the University of Manchester's Takedown Procedures [http://man.ac.uk/04Y6Bo] or contact uml.scholarlycommunications@manchester.ac.uk providing relevant details, so we can investigate your claim.

\section{OPEN ACCESS}




\title{
Structural and functional characterisation of KNNS-BNKZ lead-free piezoceramics
}

\author{
J. Tangsritrakul* and D. A. Hall
}

School of Materials, University of Manchester, Manchester M13 9PL, UK.

*Corresponding author: jirapa.tangsritrakul@manchester.ac.uk, tjirapa @ tu.ac.th

\begin{abstract}
Promising piezoelectric properties have been reported recently for lead-free 0.96( $\left.\mathrm{K}_{0.48} \mathrm{Na}_{0.52} \mathrm{Nb}_{0.95} \mathrm{Sb}_{0.05}\right)-0.04 \mathrm{Bi}_{0.5}\left(\mathrm{Na}_{0.82} \mathrm{~K}_{0.18}\right)_{0.5} \mathrm{ZrO}_{3}(\mathrm{KNNS}-\mathrm{BNKZ})$ ceramics. The presence of coexisting ferroelectric rhombohedral and tetragonal phases is thought to play a key role in their functional properties, but a thorough understanding is currently lacking. In this experiment, (1-x)KNNS-(x)BNKZ ceramics with $\mathrm{x}=0$ to 0.05 were prepared by the mixed-oxide method. High resolution synchrotron x-ray powder diffraction (SXPD) measurements reveal that the addition of BNKZ into KNNS ceramics leads to an increase of the rhombohedral-orthorhombic phase transition temperature $\left(\mathrm{T}_{\mathrm{R}-\mathrm{O}}\right)$ and a reduction of the orthorhombic-tetragonal phase transition temperature $\left(\mathrm{T}_{\mathrm{O}-\mathrm{T}}\right)$ leading to orthorhombic-tetragonal and rhombohedral-tetragonal phase coexistence at room temperature for compositions with $\mathrm{x}=0.02$ and 0.04 , respectively. By combining the results of the SXPD measurements with microstructural examination using SEM, evidence is also found for the occurrence of chemical heterogeneity, which could provide an additional means to control the functional properties. The structural observations are correlated with changes in the dielectric properties, obtained as permittivity-temperature plots, and variations in the polarisation and coercive field values, obtained from measurements of the ferroelectric hysteresis loops.
\end{abstract}


Keywords: Phase coexistence; Lead-free; Ferroelectric; Synchrotron x-ray diffraction.

\section{Introduction}

Piezoelectric ceramics are widely used in many applications as electromechanical sensors, actuators and transducers in applications such as fuel injectors, solid state motors and printers [1, 2]. In lead zirconate titanate (PZT), it is well known that compositions near the morphotropic phase boundary (MPB) give rise to materials having excellent piezoelectric properties because of rhombohedral-tetragonal (R-T) phase coexistence, which plays an important role in its electrical properties. However, lead is a toxic element that can cause health and environmental problems [1, $3,4,5]$.

Potassium sodium niobate $\left(\mathrm{K}_{\mathrm{x}} \mathrm{Na}_{1-\mathrm{x}} \mathrm{NbO}_{3}\right.$ or $\left.\mathrm{KNN}\right)$ has been considered as one of the leading lead-free piezoceramics since 2004, when Saito et al. reported high piezoelectric coefficients, comparable to those of some PZT ceramics, for a $\mathrm{Li}$, Ta and Sb modified KNN.[6] It should be possible to replace the commercial PZT devices with lead-free piezoceramics in the future by improving the piezoelectric properties and their temperature stability[7]. There are many studies that focus on the study of two phase coexistence in order to enhance piezoelectric properties of lead-free piezoceramics $[8,9$, 10, 11]. The control of polymorphic phase transitions (PPT) has been used to form coexisting phase at room temperature to improve the electrical properties [1]. It has been found that the substitution of $\left(\mathrm{Bi}_{0.5} \mathrm{Na}_{0.5}\right)^{2+},\left[\mathrm{Bi}_{0.5}\left(\mathrm{Na}_{0.7} \mathrm{~K}_{0.2} \mathrm{Li}_{0.1}\right)_{0.5}\right]^{2+}$ or $\left[\mathrm{Bi}_{0.5}\left(\mathrm{Na}_{1-\mathrm{w}} \mathrm{K}_{\mathrm{w}}\right)_{0.5}\right]^{2+}$ species can reduce $\mathrm{T}_{\mathrm{O}-\mathrm{T}}$ (orthorhombic-tetragonal transition temperature) while $\mathrm{Zr}^{4+}$ ions can increase $\mathrm{T}_{\mathrm{R}-\mathrm{O}}$ (rhombohedral-orthorhombic transition temperature). As a result, the O-T, R-O-T and R-T phase coexistence can be observed near room temperature $[8,12,13]$. 
Wang et al. [8] reported that $0.96\left(\mathrm{~K}_{0.48} \mathrm{Na}_{0.52} \mathrm{Nb}_{0.95} \mathrm{Sb}_{0.05}\right)$ 0.04Bi ${ }_{0.5}\left(\mathrm{Na}_{0.82} \mathrm{~K}_{0.18}\right)_{0.5} \mathrm{ZrO}_{3}$ ceramic, which was said to contain $\mathrm{R}-\mathrm{T}$ mixed phases, exhibited a $d_{33}$ of $490 \mathrm{pC} / \mathrm{N}$. The promising piezoelectric properties of such materials merit further investigations to clarify the relationships between their complex multiphase structure and functional properties. The aim of this experiment is to study the effects of adding $\mathrm{Bi}_{0.5}\left(\mathrm{Na}_{0.82} \mathrm{~K}_{0.18}\right)_{0.5} \mathrm{ZrO}_{3}$ (BNKZ) into $\mathrm{K}_{0.48} \mathrm{Na}_{0.52} \mathrm{Nb}_{0.95} \mathrm{Sb}_{0.05} \mathrm{O}_{3}$ (KNNS) on the phase formation using high resolution synchrotron x-ray powder diffraction (SXPD). Moreover, the effects of BNKZ on the microstructures, dielectric properties and ferroelectric properties are also investigated.

\section{Experimental procedures}

Compositions were prepared by the conventional mixed-oxide method according to the chemical formula $(1-\mathrm{x})\left(\mathrm{K}_{0.48} \mathrm{Na}_{0.52} \mathrm{Nb}_{0.95} \mathrm{Sb}_{0.05}\right)-(\mathrm{x})\left(\mathrm{Bi}_{0.5}\left(\mathrm{Na}_{0.82} \mathrm{~K}_{0.18}\right)_{0.5} \mathrm{ZrO}_{3}\right)$ with $\mathrm{x}=0$ to 0.05 , denoted as $0 \mathrm{BNKZ}$ to $5 \mathrm{BNKZ}$. The raw powders of $\mathrm{K}_{2} \mathrm{CO}_{3}(99.0 \%)$, $\mathrm{Na}_{2} \mathrm{CO}_{3}(99.8 \%), \mathrm{Nb}_{2} \mathrm{O}_{5}(99.0 \%), \mathrm{Sb}_{2} \mathrm{O}_{3}(98.0 \%), \mathrm{Bi}_{2} \mathrm{O}_{3}(99.0 \%)$ and $\mathrm{ZrO}_{2}(99.0 \%)$ were weighed according to the nominal composition. However, it is well known that carbonate powders are moisture sensitive [14]. Therefore, in this experiment, $\mathrm{K}_{2} \mathrm{CO}_{3}$ and $\mathrm{Na}_{2} \mathrm{CO}_{3}$ powders were dried overnight in an oven at $90^{\circ} \mathrm{C}$ before weighing in order to avoid non-stoichiometry of the calcined powders. Then, the raw powders were milled in isopropanol for 24 hours and calcined at $850^{\circ} \mathrm{C}$ for 6 hours.

After calcination, the calcined powders were milled again for 24 hours and dried overnight before mixing with $2 \mathrm{wt} \%$ of PEG as a binder. Next, the calcined powder were pressed under a pressure of $25 \mathrm{MPa}$ in a $8 \mathrm{~mm}$ diameter cylindrical steel die into a disc with thickness around $1 \mathrm{~mm}$. The green pellets were covered in a calcined powder 
of the same composition to avoid volatilisation of alkali oxides and sintered at $1120^{\circ} \mathrm{C}$ to $1170^{\circ} \mathrm{C}$ for 3 hours after binder burn out.

The density of the samples was measured by the Archimedes method with $\mathrm{H}_{2} \mathrm{O}$ as the immersion liquid, using the average value from three samples for each composition. The theoretical densities were calculated on the basis of the refined crystallographic parameters together with the nominal chemical composition. Crystallographic information was obtained using high resolution synchrotron x-ray powder diffraction (SXPD) on beamline I11 at the Diamond Light Source, UK using a wavelength of $0.826 \AA$. The KNNS-BNKZ ceramics were crushed into powder and compacted into borosilicate glass capillaries with a diameter of $0.3 \mathrm{~mm}$. A high resolution MAC detector, consisting of 5 banks of $9 \mathrm{Si}$ single crystal detectors, was used to scan the angular range from $10^{\circ}$ to $90^{\circ} 2 \theta$ at room temperature for 20 minutes. The full-pattern refinement was accomplished by a Rietveld refinement method using Topas, version 4.2 .

The microstructure of polished cross-sections was examined using a Philips XL30 FEGSEM in backscattered electron mode. For electrical measurements, the ceramic discs were ground to around $1 \mathrm{~mm}$ in thickness before applying and firing a silver electrode (Gwent Group type C2000107P3) at a temperature of $550^{\circ} \mathrm{C}$ for 30 minutes. The temperature dependence of dielectric permittivity of KNNS-BNKZ ceramics was measured at frequencies between 1 and $100 \mathrm{kHz}$ using a HP4284A impedance analyser over the temperature range $50^{\circ} \mathrm{C}$ to $450^{\circ} \mathrm{C}$. The ferroelectric $\mathrm{P}-\mathrm{E}$ hysteresis loops of KNNS-BNKZ ceramics were measured at room temperature. The samples were measured in a silicone oil bath to avoid electrical breakdown. Four cycles of a sinusoidal electric field with amplitude $4 \mathrm{kV} \mathrm{mm}^{-1}$ were applied at a frequency of 2 $\mathrm{Hz}$ to test the samples. The voltage-time waveforms were generated using a HP33120A 
function generator in combination with a Chevin Research HVAIB high voltage amplifier, while the induced current was measured by means of a current amplifier. The applied voltage and current waveforms were measured using a 16-bit A/D card (Measurement Computing USB-1608FS) and the P-E hysteresis loops constructed using LabVIEW software.[15]

\section{Results and discussion}

\subsection{Density}

The relative densities of the $1 \mathrm{BNKZ}$ to $5 \mathrm{BNKZ}$ ceramics were higher than $93 \%$, while that of $0 \mathrm{BNKZ}$ was lower than $90 \%$, as shown in Table 1 . This is possibly due to the incorporation of bismuth oxide, $\mathrm{Bi}_{2} \mathrm{O}_{3}$, since it was reported by $\mathrm{Du}$ [16] that the addition of $\mathrm{Bi}_{2} \mathrm{O}_{3}$ to $\mathrm{KNN}$ acts to increase the melting point and optimum sintering temperature of the solid solution. Therefore, the higher sintering temperature used with bismuth-containing compositions enhances the densification. Consequently, the composition $0 \mathrm{BNKZ}$ in our experiment, in the absence of bismuth oxide, exhibited poor density and many large pores, as illustrated by the micrograph presented in figure 4(a). Previous studies on Sb-doped KNN ceramics have employed other sintering aids such as $\mathrm{CuO}$ in their sample preparation $[17,18,19]$.

\subsection{Dielectric properties}

Figure 1 illustrates the temperature-dependence of dielectric properties for KNNS-BNKZ ceramics, measured at frequencies from 1 to $100 \mathrm{kHz}$. The Curie temperature $\left(\mathrm{T}_{\mathrm{C}}\right)$ of $0 \mathrm{BNKZ}$ occurred at $302^{\circ} \mathrm{C}$, while $\mathrm{T}_{\mathrm{O}-\mathrm{T}}$ was approximately $125^{\circ} \mathrm{C}$. The high dielectric losses of the OBNKZ ceramic, which are most prominent at high temperatures and low frequencies, indicate a relatively high conductivity associated 
with the high porosity. It is evident that the addition of BNKZ into KNNS causes shifts in the transition temperatures, reducing $\mathrm{T}_{\mathrm{C}}$ from $302^{\circ} \mathrm{C}$ to $214^{\circ} \mathrm{C}$ and $\mathrm{T}_{\mathrm{O}-\mathrm{T}}$ from $125^{\circ} \mathrm{C}$ to lower than $50^{\circ} \mathrm{C}$. These results are consistent with those of Wang [8], who reported that the substitution of $\left[\mathrm{Bi}_{0.5}\left(\mathrm{Na}_{0.82} \mathrm{~K}_{0.18}\right)_{0.5}\right]^{2+}$ in $\mathrm{KNN}$ reduces $\mathrm{T}_{\mathrm{O}-\mathrm{T}}$ as noted above. The influence of $\mathrm{Zr}^{4+}$ on $\mathrm{T}_{\mathrm{R}-\mathrm{O}}$ could not be verified in the present results. Furthermore, the addition of $\mathrm{BNKZ}$ gave rise to a relaxor ferroelectric character in the $\varepsilon_{\mathrm{r}}-\mathrm{T}$ relationships, giving rise to a broadening of the Curie peak and frequency-dependence of the permittivity at temperatures below $\mathrm{T}_{\mathrm{C}}$. The phase transformation became very diffuse for the $5 \mathrm{BNKZ}$ ceramic in comparison with the other compositions, as shown in figure 1(d). Xing [20] also observed a diffuse phase transition in KNN-based ceramics having compositions (1-x) $\left[\mathrm{K}_{0.48} \mathrm{Na}_{0.52} \mathrm{Nb}_{0.95} \mathrm{Sb}_{0.05} \mathrm{O}_{3}\right]-(\mathrm{x})\left[\left(\mathrm{Bi}_{0.5} \mathrm{Na}_{0.5}\right)_{0.9}\left(\mathrm{Li}_{0.5} \mathrm{Ce}_{0.5}\right)_{0.1} \mathrm{ZrO}_{3}\right]$ when $\mathrm{x}$ exceeded 0.045 , which was attributed to reaching the solubility limit. In terms of dielectric loss, relatively high $\tan \delta$ values were generally observed at temperatures below $T_{C}$ due to the presence of ferroelectric domains [21]. With increasing temperature, the losses reduced in the region of $\mathrm{T}_{\mathrm{C}}$, but then increased dramatically, particularly when measured at low frequencies. The frequency-dependence of $\tan \delta$ in the high temperature region is characteristic of a conduction mechanism, as described by Hardtl [21]. 

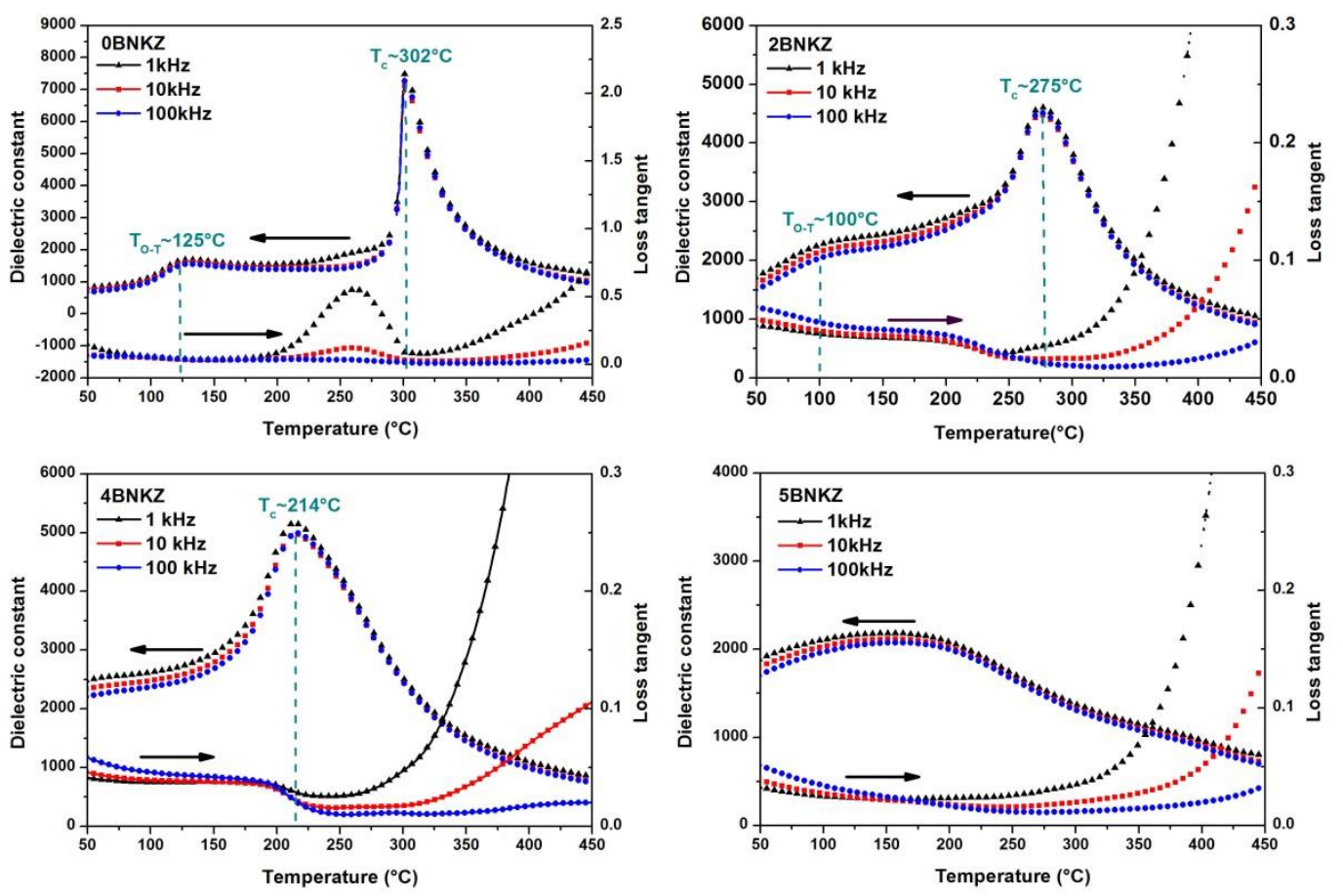

Figure 1. Temperature-dependence of dielectric properties for (a) 0BNKZ, (b) 2BNKZ, (c) 4BNKZ and (d) 5BNKZ.

\subsection{Identification of crystal structures at room temperature}

The high resolution SXPD results for KNNS-BNKZ ceramics, which illustrate the effects of introducing BNKZ on the diffraction peak profiles, are presented figure 2. It is evident that $0 \mathrm{BNKZ}$ had a predominantly orthorhombic structure, indicated by characteristic splitting of the pseudo-cubic $\{200\}_{\mathrm{p}},\{210\}_{\mathrm{p}}$ and $\{211\}_{\mathrm{p}}$ reflections, for example. The addition of BNKZ had a dramatic effect on the SXPD peak profiles at room temperature, which changed in intensity and became broader, suggesting the presence of overlapping peaks due to the coexistence of different phases. A secondary phase, tentatively identified as $\mathrm{K}_{2.75} \mathrm{Nb}_{5.45} \mathrm{O}_{15}$, was evident in the SXPD patterns of specimens with higher BNKZ contents, as indicated in figure 2(a). 

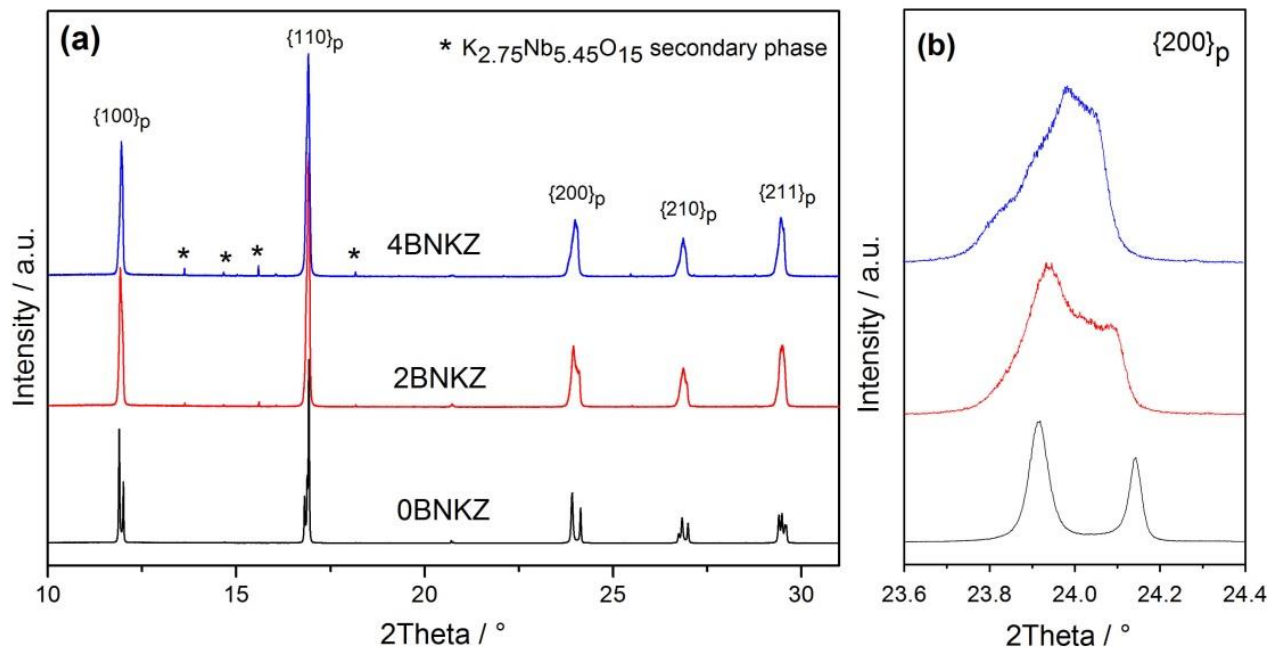

Figure 2. The SXPD peak profiles of $0 \mathrm{BNKZ}, 2 \mathrm{BNKZ}$ and $4 \mathrm{BNKZ}$ ceramics. (a) Representative diffraction patterns with pseudo-cubic indices and (b) enlargement of $(200)_{\mathrm{p}}$ peak profiles.

The single-phase orthorhombic structure for $0 \mathrm{BNKZ}$ was confirmed by fullpattern refinement, giving the results shown in figure 3(a) and Table 1. For 2BNKZ, the best fit was obtained by a 2-phase O-T mixture with a $\mathrm{T}$ content of approximately $37 \%$, as illustrated in figure 3(b). According to the dielectric property measurements shown in figure 1(b) above, the O-T transition temperature, $\mathrm{T}_{\mathrm{O}-\mathrm{T}}$, of $2 \mathrm{BNKZ}$ was approximately $100^{\circ} \mathrm{C}$, which is substantially higher than room temperature. Therefore, it is evident that the incorporation of $\mathrm{BNKZ}$ into $\mathrm{KNN}$ led to a significant broadening of the phase transition region since a significant proportion of $\mathrm{T}$ phase was still present at room temperature.

When the BNKZ content increased further, the orthorhombic phase fraction decreased and disappeared due to the combined effects of an increase of $\mathrm{T}_{\mathrm{R}-\mathrm{O}}$ and reduction of $\mathrm{T}_{\mathrm{O}-\mathrm{T}}$ as well as $\mathrm{T}_{\mathrm{C}}[8]$. As a result, an $\mathrm{R}-\mathrm{T}$ mixed phase containing approximately $56 \% \mathrm{R}$ was identified in the composition 4BNKZ. These results are consistent with those of Wang et al. [8], who inferred the presence of an R-T mixed 
phase from their temperature-dependent dielectric measurements. However, there are some peaks of $4 \mathrm{BNKZ}$ that are not well fit, as observed in both $(220)_{\mathrm{p}}$ and $(222)_{\mathrm{p}}$ reflections in figure 3(c). This is possibly a consequence of the chemical heterogeneity, as described below in section 3.4. In this study, we have been able to identify the phase coexistence in this material directly using high resolution SXPD. The volume fractions of the different coexisting phases as well as their crystallographic parameters and goodness-of-fit $\left(\chi^{2}\right)$ obtained by Rietveld refinement are summarised in Table 1 . Note that the $\chi^{2}$ in Table 1 is defined as the weight-profile $\mathrm{R}$-factor $\left(\mathrm{R}_{\mathrm{wp}}\right)$ divided by the expected R-factor $\left(\mathrm{R}_{\exp }\right)$ [22].

Table 1. Coexisting phases, phase fractions, lattice parameters, $\chi^{2}, R_{w p}$ and relative densities of $0 \mathrm{BNKZ}$ to $5 \mathrm{BNKZ}$ ceramics. Uncertainties in lattice parameters are less than $0.0001 \AA$.

\begin{tabular}{|c|c|c|c|c|c|c|c|c|c|}
\hline \multirow[b]{2}{*}{ Composition } & \multirow[b]{2}{*}{$\begin{array}{l}\text { Phases } \\
\text { present }\end{array}$} & \multirow{2}{*}{$\begin{array}{c}\text { Phase } \\
\text { fraction } \\
/ \%\end{array}$} & \multicolumn{4}{|c|}{ Lattice parameter } & \multirow[b]{2}{*}{$\chi^{2}$} & \multirow[b]{2}{*}{$\mathrm{R}_{\mathrm{wp}}$} & \multirow{2}{*}{$\begin{array}{c}\text { Relative } \\
\text { density } \\
1 \% \\
\end{array}$} \\
\hline & & & a / $\AA$ & $\mathrm{b} / \AA$ & $\mathrm{c} / \AA$ & $\alpha /{ }^{\circ}$ & & & \\
\hline OBNKZ & $\mathrm{O}$ & $O=100$ & $\mathrm{ao}=5.6272$ & bo $=3.9506$ & $\mathrm{co}=5.6495$ & - & 5.86 & 12.1 & 87 \\
\hline 1BNKZ & $\mathrm{O}-\mathrm{T}$ & $\begin{array}{l}\mathrm{O}=75 \\
\mathrm{~T}=25\end{array}$ & $\begin{aligned} \mathrm{a}_{\mathrm{O}} & =5.6227 \\
\mathrm{a}_{\mathrm{T}} & =3.9684\end{aligned}$ & $\begin{array}{c}\mathrm{b}_{\mathrm{O}}= \\
3.9513 \\
-\end{array}$ & $\begin{array}{l}\mathrm{c}_{\mathrm{O}}=5.6413 \\
\mathrm{c}_{\mathrm{T}}=3.9736\end{array}$ & - & 2.96 & 7.7 & 97 \\
\hline 2BNKZ & $\mathrm{O}-\mathrm{T}$ & $\begin{array}{l}\mathrm{O}=63 \\
\mathrm{~T}=37\end{array}$ & $\begin{array}{c}\mathrm{ao}=5.6246 \\
\mathrm{a}_{\mathrm{T}}=3.9713\end{array}$ & $\begin{array}{c}\mathrm{b}_{\mathrm{O}}= \\
3.9597 \\
-\end{array}$ & $\begin{array}{l}\mathrm{c}_{\mathrm{O}}=5.6445 \\
\mathrm{c}_{\mathrm{T}}=3.9982\end{array}$ & $\begin{array}{l}- \\
-\end{array}$ & 3.91 & 10.4 & 93 \\
\hline $3 \mathrm{BNKZ}$ & R-T & $\begin{array}{l}\mathrm{R}=20 \\
\mathrm{~T}=80\end{array}$ & $\begin{array}{l}\mathrm{aR}_{\mathrm{R}}=3.9841 \\
\mathrm{a}_{\mathrm{T}}=3.9708\end{array}$ & $\begin{array}{l}- \\
-\end{array}$ & $\mathrm{c}_{\mathrm{T}}=\overline{-} .9932$ & $\begin{array}{c}\alpha=89.72 \\
-\end{array}$ & 4.59 & 12.3 & 96 \\
\hline 4BNKZ & R-T & $\begin{array}{l}\mathrm{R}=45 \\
\mathrm{~T}=55\end{array}$ & $\begin{array}{l}\mathrm{a}_{\mathrm{R}}=3.9793 \\
\mathrm{a}_{\mathrm{T}}=3.9681\end{array}$ & $\begin{array}{l}- \\
-\end{array}$ & $\mathrm{c}_{\mathrm{T}}=\overline{-} .9976$ & $\begin{array}{c}\alpha=89.83 \\
-\end{array}$ & 5.48 & 14.9 & 96 \\
\hline $5 \mathrm{BNKZ}$ & $\mathrm{R}-\mathrm{C}$ & $\begin{array}{l}R=46 \\
C=54\end{array}$ & $\begin{array}{l}\mathrm{a}_{\mathrm{R}}=3.9779 \\
\mathrm{a}_{\mathrm{C}}=3.9756\end{array}$ & $\begin{array}{l}- \\
-\end{array}$ & $\begin{array}{l}- \\
-\end{array}$ & $\begin{array}{c}\alpha=89.83 \\
-\end{array}$ & 5.77 & 15.9 & 99 \\
\hline
\end{tabular}



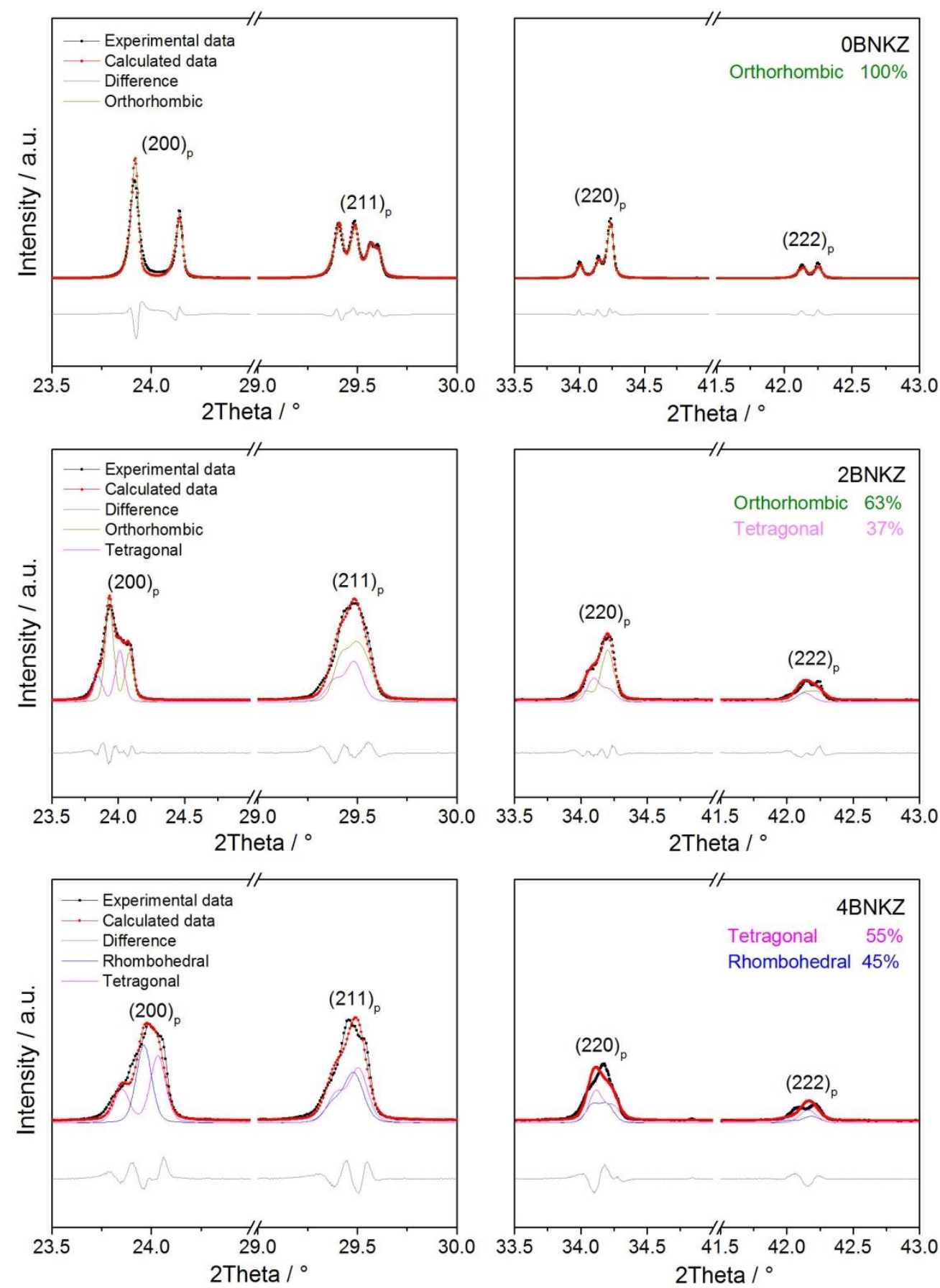

Figure 3. The measured, calculated and difference data obtained by full-pattern refinement showing $(200)_{\mathrm{p}},(211)_{\mathrm{p}},(220)_{\mathrm{p}}$ and $(222)_{\mathrm{p}}$ reflections of (a) single O phase in OBNKZ, (b) O-T coexisting phases in 2BNKZ and (c) R-T coexisting phases in 4BNKZ. 


\subsection{Microstructural observations}

The cross-sectional microstructures of $0 \mathrm{BNKZ}$ and $2 \mathrm{BNKZ}$ ceramics were investigated in order to study on the effect of $\mathrm{BNKZ}$ on the grain size, illustrated in figure 4. It was found that the abnormal grain growth was observed in both $0 \mathrm{BNKZ}$ and 2BNKZ, with average grain sizes around $15.7 \pm 3.3 \mu \mathrm{m}$ and $1.3 \pm 0.5 \mu \mathrm{m}$, respectively. Malic [23] reported that secondary phases can possibly lead to the occurrence of abnormal grain growth in KNN-based ceramics.

Examination of the BNKZ-modified KNN ceramics revealed the occurrence of core-shell type microstructures, as shown in figure 4(b) for 2BNKZ. A second phase was also observed as lighter regions in the BSE images; this was identified as $\mathrm{K}_{2.75} \mathrm{Nb}_{5.45} \mathrm{O}_{15}$ by $\mathrm{SXPD}$, as noted above in section 3.3 and figure 2(a). Similar microstructures were observed in all other compositions except 0BNKZ, suggesting the presence of chemical heterogeneity $[24,25,26]$. The formation of core-shell type microstructures has been explained by exceeding the solubility limit of dopants, raw material heterogeneity or strain gradients that lead to controlled or suppressed diffusion processes [24]. In this study, it was found that it was not possible to eliminate the coreshell structures by using a longer sintering time of up to 6 hours.
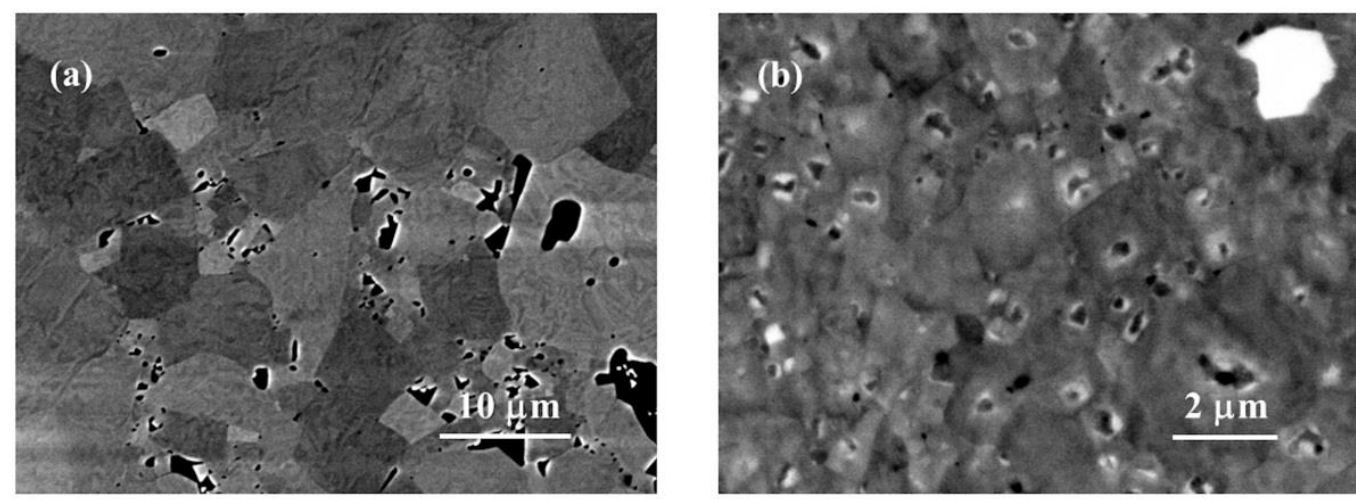
Figure 4. Polished cross-sections of KNNS-BNKZ ceramics observed by BSE imaging (a) abnormal grain growth in $0 \mathrm{BNKZ}$ and (b) core-shell microstructure in $2 \mathrm{BNKZ}$ with lighter grains of $\mathrm{K}_{2.75} \mathrm{Nb}_{5.45} \mathrm{O}_{15}$ secondary phase.

Additional high temperature SXPD measurements were undertaken to provide further evidence for this type of chemical segregation. It is anticipated that a chemically-homogeneous KNN ceramic should transform to a cubic structure, with no splitting of the diffraction peaks, at temperatures above the Curie point. In the present case, evidence was found for a persistent shoulder on all of the diffraction peaks for 2BNKZ measured at $337^{\circ} \mathrm{C}$, well above its Curie temperature of $\sim 276^{\circ} \mathrm{C}$, as shown by the results presented in figure 5 for the $2 \mathrm{BNKZ}$ composition. A similar feature was also observed in the diffraction patterns for all of the compositions containing BNKZ, becoming more pronounced with increasing BNKZ content. This is attributed to the occurrence of a core-shell type microstructure comprising two cubic phases having different average chemical compositions and lattice parameters, which were determined as $\mathrm{a}_{\text {core }}=3.9793 \AA$ and $\mathrm{a}_{\text {shell }}=3.9885 \AA$. The lattice strain between these phases is approximately $0.23 \%$. Further investigation of the local variations in crystal symmetry and chemical composition using high resolution TEM would help to clarify the nature and origin of the core-shell microstructure. 

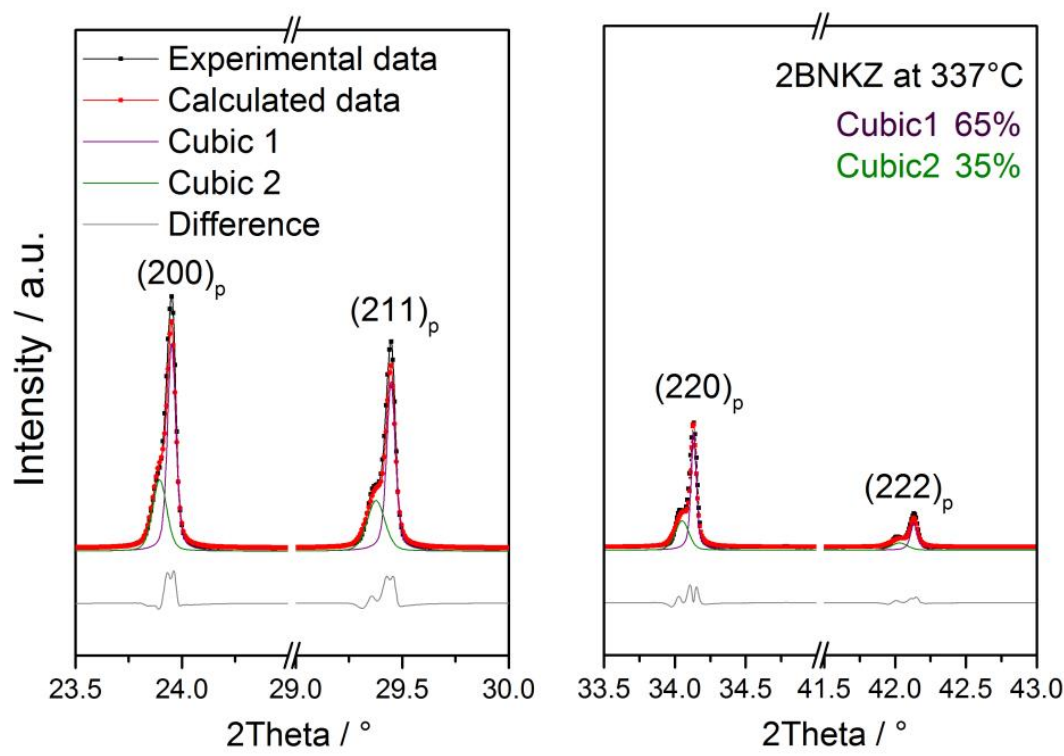

Figure 5. Full-pattern refinement of $2 \mathrm{BNKZ}$ ceramic at $337^{\circ} \mathrm{C}$ showing $(200)_{\mathrm{p}},(211)_{\mathrm{p}}$, $(220)_{\mathrm{p}}$ and $(222)_{\mathrm{p}}$ reflections of coexisting cubic phases with two lattice parameters due to core-shell microstructure.

\subsection{Ferroelectric properties}

The ferroelectric polarisation-electric field (P-E) hysteresis loops obtained for the KNNS-BNKZ ceramics are illustrated in figure 6. With increasing BNKZ content from $1 \mathrm{BNKZ}$ to $5 \mathrm{BNKZ}$, the saturation polarisation $\left(\mathrm{P}_{\mathrm{s}}\right)$, remnant polarisation $\left(\mathrm{P}_{\mathrm{r}}\right)$ and coercive field $\left(\mathrm{E}_{\mathrm{c}}\right)$ decreased from 0.24 to $0.12 \mathrm{C} / \mathrm{m}^{2}, 0.18$ to $0.03 \mathrm{C} / \mathrm{m}^{2}$, and 1.69 to $0.82 \mathrm{kV} / \mathrm{mm}$, respectively. A strongly rounded loop was obtained for 0BNKZ, which was attributed to the effects of a relatively high electrical conductivity, consistent with the dielectric results presented in figure 1 above. These results show that the addition of the relaxor ferroelectric BNKZ could enhance the domain switching in $\mathrm{KNN}$, giving rise to a reduction in $\mathrm{E}_{\mathrm{c}}$ but with an associated reduction in $\mathrm{P}_{\mathrm{r}}$. For comparison, $\mathrm{Wu}$ [9] found the highest saturation polarisation of around $0.2 \mathrm{C} / \mathrm{m}^{2}$ for the composition 
$0.96 \mathrm{~K}_{0.46} \mathrm{Na}_{0.54} \mathrm{Nb}_{0.95} \mathrm{Sb}_{0.05} \mathrm{O}_{3}-0.04 \mathrm{Bi}_{0.5}\left(\mathrm{Na}_{0.82} \mathrm{~K}_{0.18}\right)_{0.5} \mathrm{ZrO}_{3}$, which is slightly higher than that observed in the present study.

It was anticipated that the addition of BNKZ should lead to a general increase in polarisation due to the occurrence of O-T and R-T phase coexistence. However, in this study it was found that both $\mathrm{P}_{\mathrm{s}}$ and $\mathrm{P}_{\mathrm{r}}$ gradually decreased with increasing BNKZ content. This is possibly due to the reduction of grain size, which is known to cause a decrease of remnant polarisation [9]. Furthermore, the core-shell type microstructure could have an additional effect on the polarisation switching characteristics. In contrast, Ochoa et al. [27] found that $\left(\mathrm{K}_{0.44} \mathrm{Na}_{0.52} \mathrm{Li}_{0.04}\right)\left(\mathrm{Nb}_{0.86} \mathrm{Ta}_{0.10} \mathrm{Sb}_{0.06}\right) \mathrm{O}_{3}$ ceramic showed increases in $\mathrm{P}_{\mathrm{s}}$ and $\mathrm{P}_{\mathrm{r}}$ with increasing temperature due to the $\mathrm{O}-\mathrm{T}$ phase transformation and reached the highest point at the temperature associated with the O-T mixed phase.

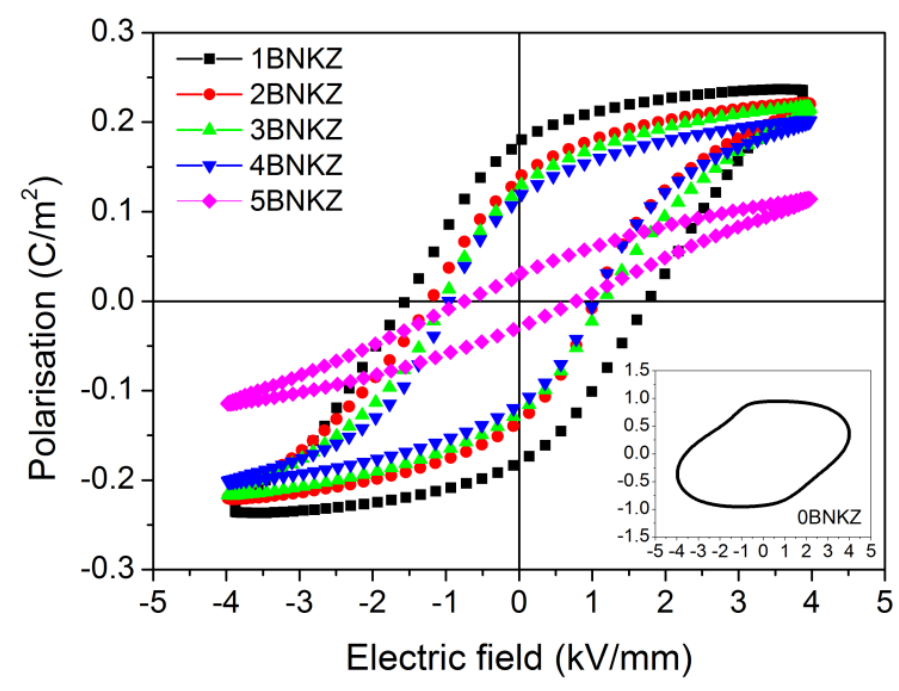

Figure 6. P-E hysteresis loops of $1 \mathrm{BNKZ}$ to $5 \mathrm{BNKZ}$ ceramics measured at room temperature.

\section{Conclusions}

Measurements of the temperature-dependent dielectric properties showed that the addition of BNKZ into KNNS leads to a reduction of the orthorhombic to tetragonal 
phase transformation temperature, $\mathrm{T}_{\mathrm{O}-\mathrm{T}}$. Moreover, the relaxor ferroelectric behaviour was observed in KNNS-BNKZ ceramics. By combining the dielectric results with high resolution synchrotron XRD, it was confirmed that the addition of BNKZ into KNNS causes $\mathrm{O}-\mathrm{T}$ and $\mathrm{R}-\mathrm{T}$ phase coexistence in $2 \mathrm{BNKZ}$ and $4 \mathrm{BNKZ}$, respectively, which is consistent with previous observations [8]. However, the occurrence of core-shell type microstructures in KNNS-BNKZ ceramics due to chemical heterogeneity showed the strong effect on phase formation as well as the functional properties.

\section{Acknowledgements}

We thank Diamond Light Source for access to beamline I11 (proposal number EE13116) that contributed to the results presented here. The assistance of Dr Sarah Day and Prof Chiu Tang is gratefully acknowledged. Also, JT would like to thank Thammasat University for financial support in the form of a $\mathrm{PhD}$ scholarship at the University of Manchester.

\section{Reference}

1. Rodel J, Jo W, Seifert KTP, Anton EM, Granzow T, Damjanovic D. Perspective on the Development of Lead-free Piezoceramics. Journal of the American Ceramic Society. 2009;92:1153-77.

2. Rodel J, Webber KG, Dittmer R, Jo W, Kimura M, Damjanovic D. Transferring lead-free piezoelectric ceramics into application. J Eur Ceram Soc. 2015;35:1659-81.

3. Guo R, Cross LE, Park SE, Noheda B, Cox DE, Shirane G. Origin of the High Piezoelectric Response in $\mathrm{PbZr}_{1-\mathrm{x}} \mathrm{Ti}_{\mathrm{x}} \mathrm{O}_{3}$. Physical Review Letters. 2000;84:5423-6.

4. Panda PK, Sahoo B. PZT to Lead Free Piezo Ceramics: A Review. Ferroelectrics. 2015;474:128-43. 
5. Ringgaard E, Wurlitzer T. Lead-free piezoceramics based on alkali niobates. J Eur Ceram Soc. 2005;25:2701-6.

6. Saito Y, Takao H, Tani T, Nonoyama T, Takatori K, Homma T, Nagaya T, Nakamura M. Lead-free piezoceramics. Nature. 2004;432:84-7.

7. Baker DW, Thomas PA, Zhang N, Glazer AM. A comprehensive study of the phase diagram of $\mathrm{K}_{\mathrm{x}} \mathrm{Na}_{1-\mathrm{x}} \mathrm{NbO}_{3}$. Applied Physics Letters. 2009;95: 091903.

8. Wang XP, Wu JG, Xiao DQ, Zhu JG, Cheng XJ, Zheng T, Zhang BY, Lou XJ, Wang XJ. Giant Piezoelectricity in Potassium-Sodium Niobate Lead-Free Ceramics. J Am Chem Soc. 2014;136:2905-10.

9. Wu JG, Wang XP, Cheng XJ, Zheng T, Zhang BY, Xiao DQ, Zhu JG, Lou XJ. New potassium-sodium niobate lead-free piezoceramic: Giant $\mathrm{d}_{33}$ vs. sintering temperature. Journal of Applied Physics. 2014;115: 114104.

10. Liu B, Zhang Y, Li P, Shen B, Zhai J. Phase transition and electrical properties of $\mathrm{Bi}_{0.5}\left(\mathrm{Na}_{0.8} \mathrm{~K}_{0.2}\right)_{0.5} \mathrm{ZrO}_{3}$ modified $\left(\mathrm{K}_{0.52} \mathrm{Na}_{0.48}\right)\left(\mathrm{Nb}_{0.95} \mathrm{Sb}_{0.05}\right) \mathrm{O}_{3}$ lead-free piezoelectric ceramics. Ceramics International. 2016;42:13824-9.

11. Kang WS, Koh JH. (1-x) $\mathrm{Bi}_{0.5} \mathrm{Na}_{0.5} \mathrm{TiO}_{3}-\mathrm{xBaTiO}_{3}$ lead-free piezoelectric ceramics for energy-harvesting applications. J Eur Ceram Soc. 2015;35:2057-64.

12. Cheng XJ, Wu JG, Wang XP, Zhang BY, Zhu JG, Xiao DQ, Wang XJ, Lou XJ. Giant $\mathrm{d}_{33}$ in $(\mathrm{K}, \mathrm{Na})(\mathrm{Nb}, \mathrm{Sb}) \mathrm{O}_{3}-(\mathrm{Bi}, \mathrm{Na}, \mathrm{K}, \mathrm{Li}) \mathrm{ZrO}_{3}$ based lead-free piezoelectrics with high $T_{c}$. Applied Physics Letters. 2013;103: 052906.

13. Zhang BY, Wu JG, Cheng XJ, Wang XP, Xiao DQ, Zhu JG, Wang XJ, Lou XJ. Lead-free Piezoelectrics Based on Potassium-Sodium Niobate with Giant $\mathrm{d}_{33}$. ACS Appl Mater Interfaces. 2013;5:7718-25. 
14. Bomlai P, Wichianrat P, Muensit S, Milne SJ. Effect of calcination conditions and excess alkali carbonate on the phase formation and particle morphology of $\mathrm{Na}_{0.5} \mathrm{~K}_{0.5} \mathrm{NbO}_{3}$ powders. Journal of the American Ceramic Society. 2007;90:1650-5.

15. Stewart M, Cain MG, Hall DA. Ferroelectric Hysteresis Measurement \& Analysis. Teddington: National Physical Laboratory, 1999.

16. Du HL, Luo F, Qu SB, Pei ZB, Zhu DM, Zhou WC. Phase structure, microstructure, and electrical properties of bismuth modified potassium-sodium niobium lead-free ceramics. Journal of Applied Physics. 2007;102:054102.

17. Fu J, Zuo R, Qi H, Zhang C, Li J, Li L. Low electric-field driven ultrahigh electrostrains in Sb-substituted $(\mathrm{Na}, \mathrm{K}) \mathrm{NbO}_{3}$ lead-free ferroelectric ceramics. Applied Physics Letters. 2014;105:242903.

18. Hu Q, Du H, Feng W, Chen C, Huang Y. Studying the roles of $\mathrm{Cu}$ and $\mathrm{Sb}$ in $\mathrm{K}_{0.48} \mathrm{Na}_{0.52} \mathrm{NbO}_{3}$ lead-free piezoelectric ceramics. Journal of Alloys and Compounds. 2015;640:327-34.

19. Zuo R, Fu J, Lv D, Liu Y. Antimony Tuned Rhombohedral-Orthorhombic Phase Transition and Enhanced Piezoelectric Properties in Sodium Potassium Niobate. Journal of the American Ceramic Society. 2010;93:2783-7.

20. Xing J, Tan Z, Jiang L, Chen Q, Wu J, Zhang W, Xiao D, Zhu J. Phase structure and piezoelectric properties of $(1-\mathrm{x}) \mathrm{K}_{0.48} \mathrm{Na}_{0.52} \mathrm{Nb}_{0.95} \mathrm{Sb}_{0.05} \mathrm{O}_{3}$ $\mathrm{x}\left(\mathrm{Bi}_{0.5} \mathrm{Na}_{0.5}\right)_{0.9}\left(\mathrm{Li}_{0.5} \mathrm{Ce}_{0.5}\right)_{0.1} \mathrm{ZrO}_{3}$ lead-free piezoelectric ceramics. Journal of Applied Physics. 2016;119:034101.

21. Härdtl KH. Electrical and mechanical losses in ferroelectric ceramics. Ceramics International. 1982;8:121-7.

22. McCusker LB, Von Dreele RB, Cox DE, Louer D, Scardi P. Rietveld refinement guidelines. Journal of Applied Crystallography. 1999;32:36-50. 
23. Malic B, Koruza J, Hrescak J, Bernard J, Wang K, Fisher JG, Bencan A. Sintering of Lead-Free Piezoelectric Sodium Potassium Niobate Ceramics. Materials. 2015;8:8117-46.

24. Acosta M, Schmitt LA, Molina-Luna L, Scherrer MC, Brilz M, Webber KG, Deluca M, Kleebe H-J, Rödel J, Donner W. Core-Shell Lead-Free Piezoelectric Ceramics: Current Status and Advanced Characterization of the $\mathrm{Bi}_{1 / 2} \mathrm{Na}_{1 / 2} \mathrm{TiO}_{3}-\mathrm{SrTiO}_{3}$ System. Journal of the American Ceramic Society. 2015;98:3405-22.

25. Wang Y, Damjanovic D, Klein N, Hollenstein E, Setter N. Compositional Inhomogeneity in Li- and Ta-Modified $(\mathrm{K}, \mathrm{Na}) \mathrm{NbO}_{3}$ Ceramics. Journal of the American Ceramic Society. 2007;90:3485-9.

26. Yasukawa K, Nishimura M, Nishihata Y, Mizuki Ji. Core-Shell Structure Analysis of $\mathrm{BaTiO}_{3}$ Ceramics by Synchrotron X-Ray Diffraction. Journal of the American Ceramic Society. 2007;90:1107-11.

27. Ochoa DA, Esteves G, Jones JL, Rubio-Marcos F, Fernández JF, García JE. Extrinsic response enhancement at the polymorphic phase boundary in piezoelectric materials. Applied Physics Letters. 2016;108:142901. 


\section{List of figure captions}

Figure 1. Temperature-dependence of dielectric properties for (a) 0BNKZ, (b) 2BNKZ, (c) 4BNKZ and (d) 5BNKZ.

Figure 2. The SXPD peak profiles of $0 \mathrm{BNKZ}, 2 \mathrm{BNKZ}$ and $4 \mathrm{BNKZ}$ ceramics. (a) Representative diffraction patterns with pseudo-cubic indices and (b) enlargement of $(200)_{\mathrm{p}}$ peak profiles.

Figure 3. The measured, calculated and difference data obtained by full-pattern refinement showing $(200)_{\mathrm{p}},(211)_{\mathrm{p}},(220)_{\mathrm{p}}$ and $(222)_{\mathrm{p}}$ reflections of (a) single $\mathrm{O}$ phase in $0 \mathrm{BNKZ}$, (b) $\mathrm{O}-\mathrm{T}$ coexisting phases in $2 \mathrm{BNKZ}$ and (c) RT coexisting phases in $4 \mathrm{BNKZ}$.

Figure 4. Polished cross-sections of KNNS-BNKZ ceramics observed by BSE imaging (a) abnormal grain growth in $0 \mathrm{BNKZ}$ and (b) core-shell microstructure in $2 \mathrm{BNKZ}$ with lighter grains of $\mathrm{K}_{2.75} \mathrm{Nb}_{5.45} \mathrm{O}_{15}$ secondary phase.

Figure 5. Full-pattern refinement of $2 \mathrm{BNKZ}$ ceramic at $337^{\circ} \mathrm{C}$ showing $(200)_{\mathrm{p}}$, $(211)_{\mathrm{p}},(220)_{\mathrm{p}}$ and $(222)_{\mathrm{p}}$ reflections of coexisting cubic phases with two lattice parameters due to core-shell microstructure.

Figure 6. P-E hysteresis loops of $1 \mathrm{BNKZ}$ to $5 \mathrm{BNKZ}$ ceramics measured at room temperature. 